\title{
Silicone oil injection in the treatment of massive preretinal retraction. II. Late complications in 93 eyes
}

\author{
P. K. LEAVER, R. H. B. GREY, AND A. GARNER \\ From the Retinal Unit, Moorfields Eye Hospital, City Road, London, and the Department of Pathology, \\ Institute of Ophthalmology, Judd Street, London
}

SUMMARY Long-term assessment of eyes in which silicone oil injection had been used in the treatment of retinal detachment with massive preretinal retraction was undertaken in 92 consecutive patients. While a high incidence of complications, particularly cataract, was confirmed, this study showed that they were probably caused not by any toxic effect of silicone oil but by obstruction of normal metabolic exchange at the silicone-tissue interface. The incidence of complications causing deterioration of vision or serious symptoms was not found to be high, and navigating vision was well preserved.

The use of silicone oil injection in the treatment of massive preretinal retraction is associated with a high incidence of late complications (Watzke, 1967; Okun, 1968; Cockerham et al., 1969; Grey and Leaver, 1977), yet the importance of these has not been established. Furthermore, it is accepted that the use of this technique in the treatment of otherwise irreversible retinal detachments is justified when the fellow eye is impaired or at risk (Okun, 1968; Mukai et al., 1972; Grey and Leaver, 1977). The purpose of this paper is to report the late complications of silicone oil injection and to assess their effect on visual function. A single case report is presented to provide histological evidence of the changes associated with intraocular silicone oil.

\section{Patients and methods}

Ninety-three eyes in 92 consecutive patients who had undergone silicone oil injection (Grey and Leaver, 1979) and for whom follow-up data were available for 1 year or more after surgery were assessed. Documentation was undertaken at 1, 2, 3, and 4 years after surgery, and assessment included a careful examination of the cornea, anterior chamber angle, lens, and retrolental space with slit-lamp biomicroscopy and gonioscopy. Electrodiagnostic studies were undertaken in 13 cases.

\section{Results}

INCIDENCE OF LATE COMPLICATIONS

Cataract. After 1 year 30 out of 61 phakic eyes

Address for reprints: P. K. Leaver, FRCS, Moorfields Eye Hospital, City Road, London WCl
Table 1 Cataract

\begin{tabular}{rlrl}
\hline At 1 year & $(61$ eyes $)$ & 30 & $(49 \%)$ \\
At 2 years & $(35$ eyes $)$ & 26 & $(74 \%)$ \\
$\begin{array}{r}\text { At } 3 \text { years } \\
\text { or more }\end{array}$ & $(20$ eyes $)$ & 13 & $(65 \%)$ \\
\hline
\end{tabular}

Table 2 Glaucoma

\begin{tabular}{llll}
\hline Pathogenesis & $\begin{array}{l}\text { Phakic } \\
(7 \text { eyes })\end{array}$ & $\begin{array}{l}\text { Aphakic } \\
(7 \text { eyes })\end{array}$ & $\begin{array}{l}\text { Total } \\
(14 \text { eyes })\end{array}$ \\
\hline Chronic simple & 2 & 2 & 4 \\
Closed angle & 2 & 3 & 5 \\
Oil in angle only & 2 & 1 & 3 \\
Unknown & 1 & 1 & 2 \\
\hline
\end{tabular}

(49\%) exhibited some degree of clinically recognisable lens changes which were not present before surgery. The incidence of this finding rose to $74 \%$ of 35 eyes assessed at 2 years and was $65 \%$ in 25 eyes after 3 years (Table 1). The type and extent of the lens changes varied from mild posterior subcapsular opacities to dense opacities of the lens nucleus and cortex (Fig. 1).

Glaucoma. Persistently raised intraocular pressure of more than $22 \mathrm{mmHg}$ was recorded in 14 (7 phakic and 7 aphakic) out of 93 eyes $(15 \%)$, and in 9 of these fine globules of silicone oil were found in the anterior chamber angle. In 3 eyes this was the only abnormality identified, while in the remaining 11 a history of pre-existing chronic simple glaucoma was found in 4, angle closure was present in 5, and in 2 there was no identifiable abnormality (Table 2).

Gonioscopic findings. Minute globules of silicone 
oil were found in the angle of the anterior chamber superiorly in $26(43 \%)$ phakic and $11(34 \%)$ aphakic eyes examined after 1 year or longer. Closure of the drainage angle ranging from 10 to $100 \%$ was found in 27 eyes; in 12 the extent of closure was greater than $50 \%$, and in 5 of these fine particles of
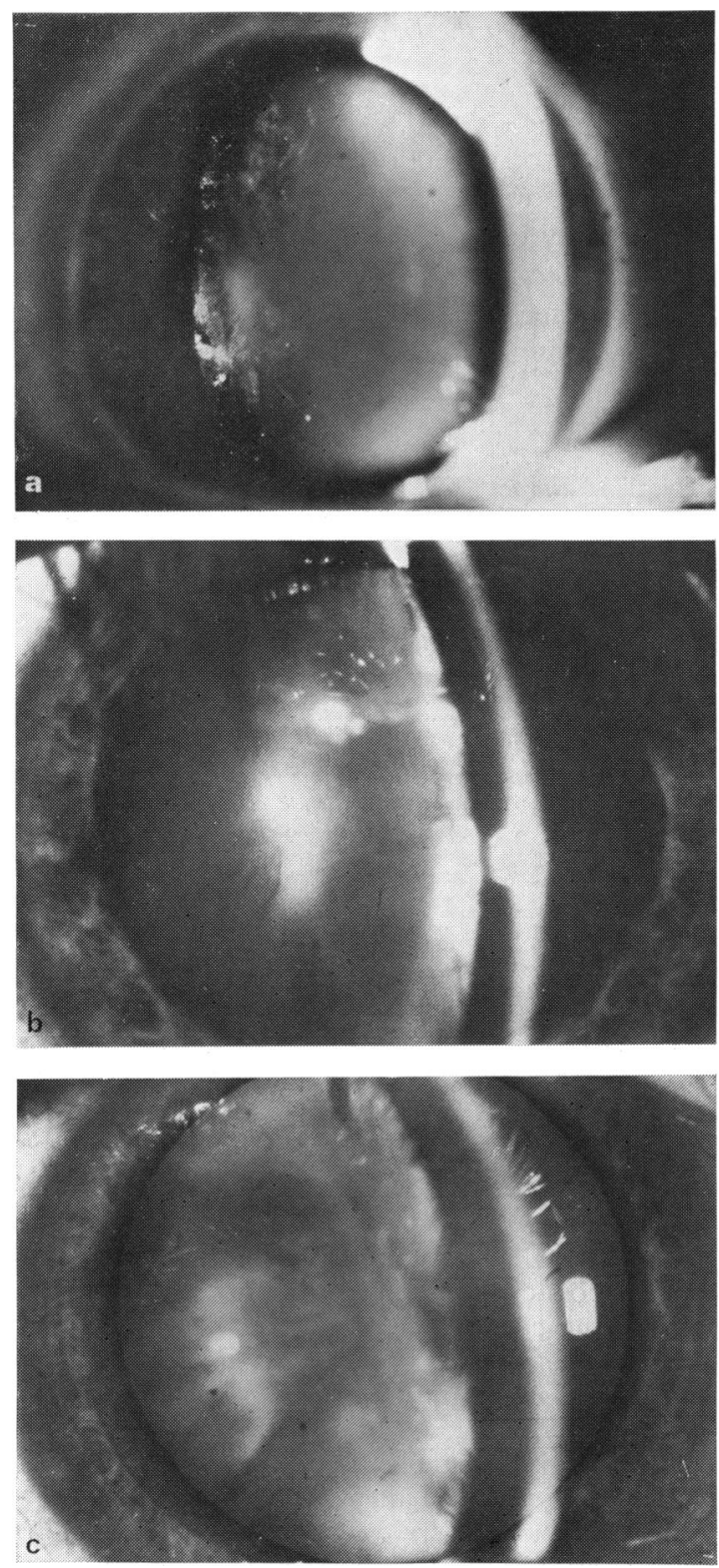

Fig. 1 (a) Posterior subcapsular lens opacities 2 years after silicone oil injection. (b) Opacities in the nucleus and cortex 18 months after silicone oil injection.

(c) Dense cataract 2 years after silicone oil injection
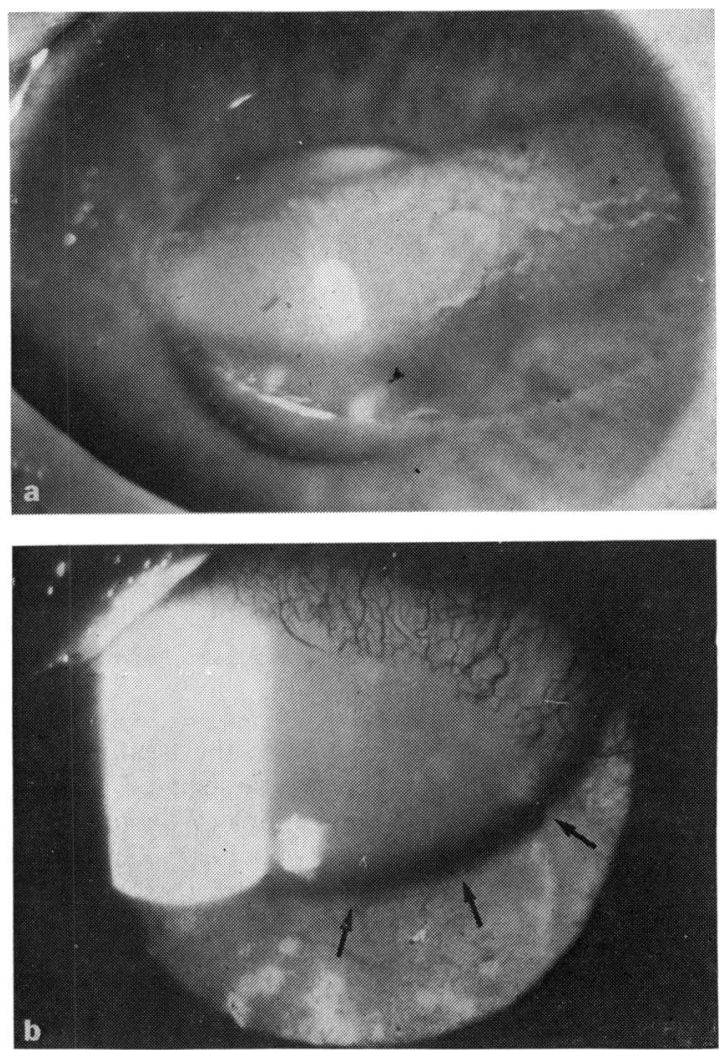

Fig. 2 (a) Band-shaped keratopathy 1 year after silicone oil injection. (b) Vascularised keratopathy 18 months after silicone oil injection. Arrows indicate the lower margin of the silicone oil globule in the anterior chamber

silicone oil were present in the anterior chamber. Keratopathy. Band-shaped and/or vascularised keratopathy (Fig. 2) was identified in 5 aphakic and 1 phakic eye. Of these 6 eyes 5 had a single large oil bubble in the anterior chamber (Fig. $3 a$ ), but in 1 the corneal changes were associated with a history of multiple needlings for congenital cataract, and no oil was present in the anterior chamber (Table 3). In the single phakic eye oil entered the anterior chamber during a trabeculectomy operation 2 years after silicone oil injection (Fig. $3 b$ ).

EFFECTS OF LATE COMPLICATIONS IN ANATOMICALLY SUCCESSFUL CASES

In 51 eyes in which the retina remained attached throughout the follow-up period the early postoperative acuity was maintained or improved in 34 $(67 \%)$, while in $17(33 \%)$ it deteriorated. Of the 34 eyes in which the initial postoperative vision was maintained or improved $38 \%$ had late complica- 
tions, whereas in the 17 which deteriorated the comparable figure was $76 \%$ (Fig. 4).

\section{ELECTRODIAGNOSTIC STUDIES IN}

ANATOMICALLY SUCCESSFUL CASES

In 13 eyes in which the retina was reattached after silicone oil injection electroretinography was carried out; 9 showed positive responses, though the potential was much less than in normal eyes, and in 4 there was no response. The electroculogram done in 10 cases showed no light rise in 9 and a good

Table 3 Keratopathy

\begin{tabular}{llll}
\hline $\begin{array}{l}\text { Oil in anterior } \\
\text { chamber }\end{array}$ & $\begin{array}{l}\text { Phakic } \\
(1 \text { eye })\end{array}$ & $\begin{array}{l}\text { Aphakic } \\
(5 \text { eyes })\end{array}$ & $\begin{array}{l}\text { Total } \\
(6 \text { eyes })\end{array}$ \\
\hline Present & $1^{*}$ & 4 & 5 \\
Absent & 0 & 1 & 1
\end{tabular}

Occurred after trabeculectomy
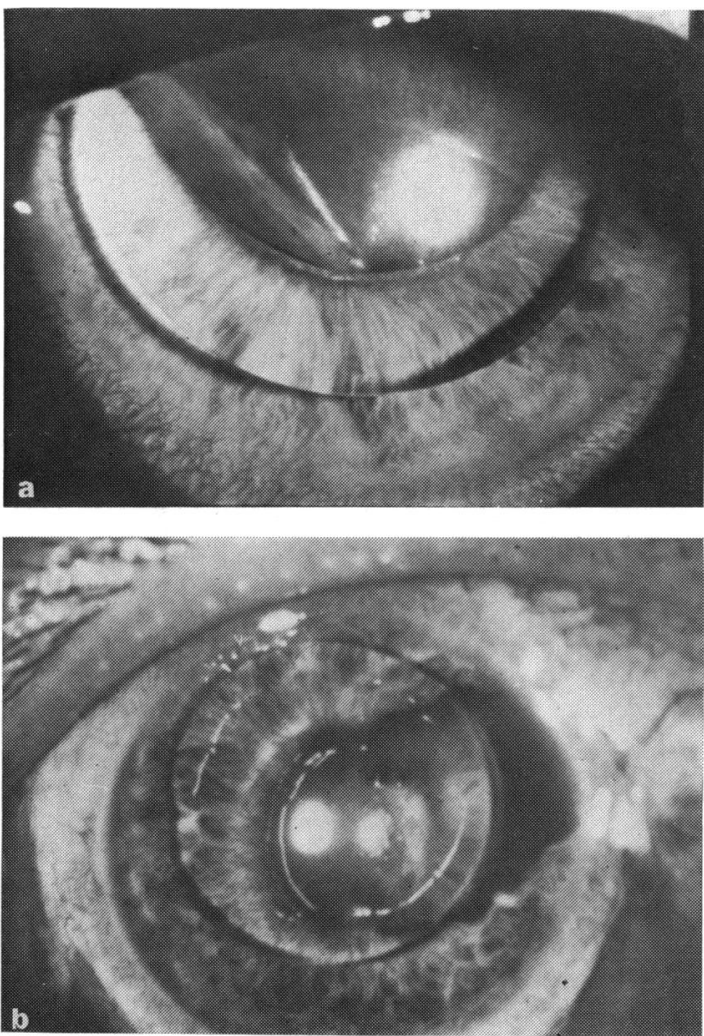

Fig. 3 (a) Large globule of silicone oil in the anterior chamber 1 year after silicone oil injection in an aphakic eye. (b) Large silicone oil globule in the anterior chamber of a phakic eye following trabeculectomy 2 years after the injection of silicone oil

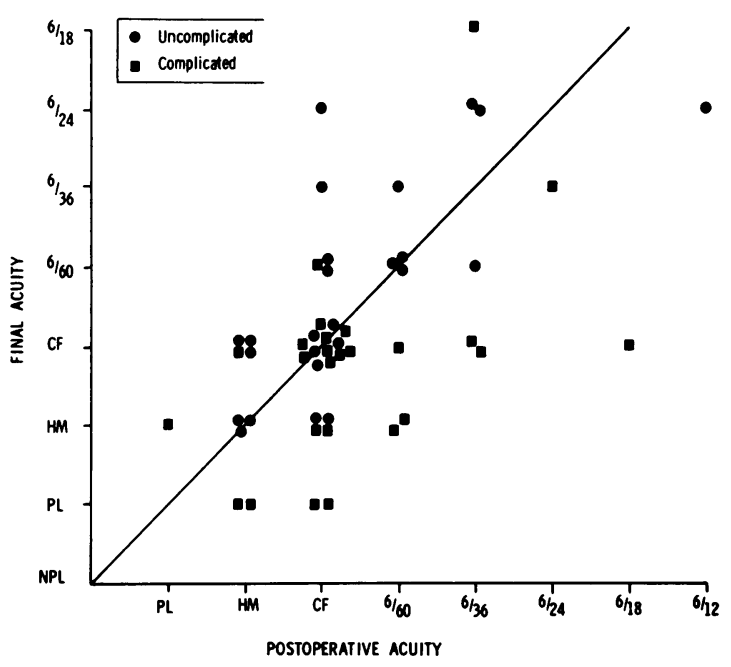

Fig. 4 Scattergram comparing the early postoperative to the final visual acuity in 51 eyes in which the retina remained attached throughout the follow-up period. Points above the line show an improvement during the postoperative period, points on the line show no change in the postoperative vision, and points below indicate a deterioration

light rise $(200 \%)$ in 1 , but with a very low standing potential.

\section{Case report}

A 33-year-old woman was admitted to Moorfields Hospital in March 1974 with a bullous retinal detachment in the right eye associated with a large operculated U-tear. Intraocular pressures were $14 \mathrm{mmHg}$ in each eye. The following day she underwent a buckling procedure with local explant and cryotherapy, during which the sclera was perforated accidentally by a suture needle, causing escape of subretinal fluid but without haemorrhage. After this procedure the retina failed to flatten because the tear was not adequately closed by the buckle, and 2 weeks later the Silastic sponge explant was replaced, with subsequent retinal reattachment. Visual acuity was reduced to counting fingers at $1 \mathrm{~m}$, due to previous macular detachment.

In July 1974 the retinal detachment recurred in the right eye, with evidence of massive preretinal retraction. On 29 July $4 \mathrm{ml}$ of silicone oil $(1000 \mathrm{cSt})$ was injected into the retrohyaloid space via the pars plana. Subretinal fluid was drained, and the retina was reapposed to the pigment epithelium. After this procedure the visual acuity improved to $6 / 60$ in the right eye.

No complications were noted until October 1976, 


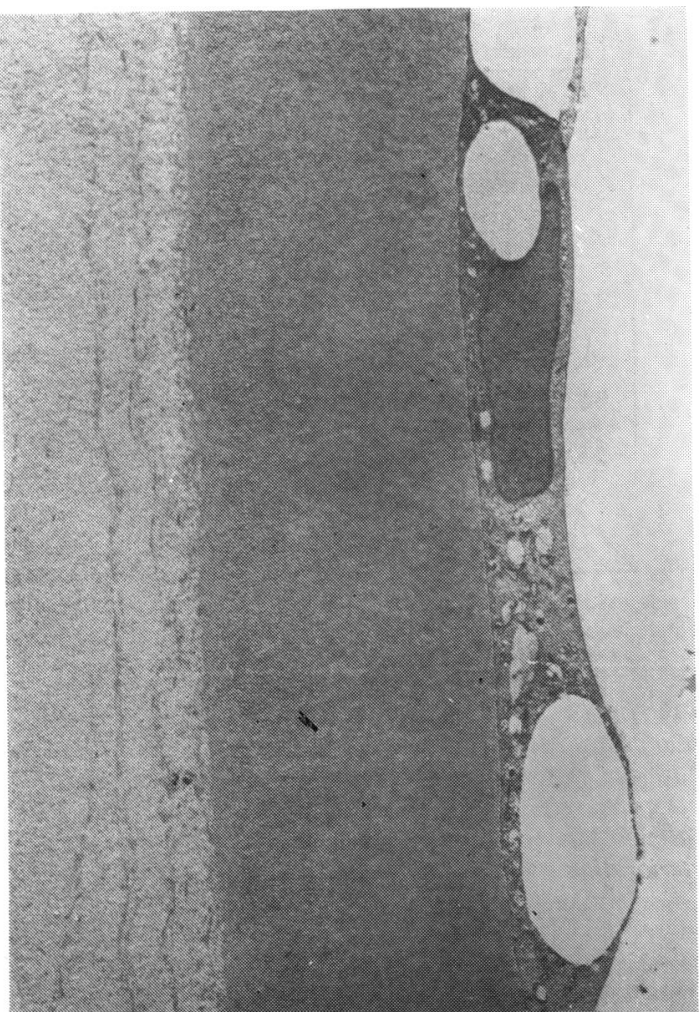

Fig. 5 Electron micrograph of posterior cornea showing endothelial cells which contain large intracytoplasmic vacuoles filled with flocculent material. Glutaraldelyde| $\mathrm{OsO}_{4} /$ uranyl acetate/lead citrate $(\times 3000)$

when she was observed to have an intraocular pressure of $46 \mathrm{mmHg}$ in the right eye and there was a fine emulsion of silicone oil globules in the anterior chamber; the intraocular pressure in the left eye was $24 \mathrm{mmHg}$ at this time. In November 1976 trabeculectomy was carried out in the right eye, and the oil globules were washed out of the anterior chamber. This procedure was uneventful, and after surgery the intraocular pressure was well controlled. During the subsequent months, however, the right eye became soft, rubeotic, and painful, with recurrent hyphaemata, and in March 1977 the right eye was enucleated.

\section{HISTOLOGICAL FINDINGS}

Light microscopy. Sections taken from the cornea, anterior chamber angle, lens, and retina of the enucleated eye were examined by light microscopy. Vacuoles of varying sizes which had presumably been occupied by silicone oil were found in the corneal endothelium, trabecular meshwork, on the anterior and posterior surfaces of the lens, and on the retina, both lying free and within the cytoplasm of macrophages.

\section{ELECTRON MICROSCOPY}

Cornea. The cytoplasm of some endothelial cells showed large membrane-bound vacuoles which were either empty or contained granular flocculent material and which probably represented phagocytic activity (Fig. 5). Occasional cells showed early degenerative change in the form of mitochondrial swelling, but advanced necrosis was not seen, and there was no apparent disturbance of Descemet's membrane or the deep stromal lamellae.

Trabecular meshwork. The trabeculae appeared to be normal with prominent long-spaced collagen and an intact endothelial lining. The spaces between

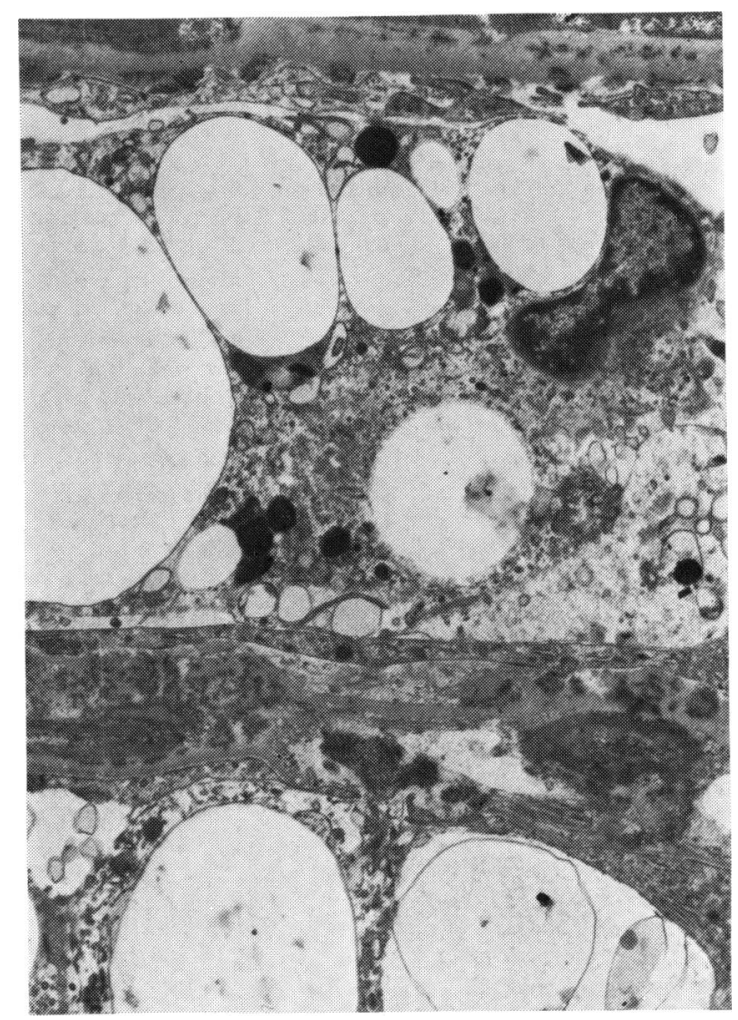

Fig. 6 Electron micrograph of the filtration angle of the anterior chamber showing part of the trabecular meshwork, the cores of which include elastic fibres and long-spacing collagen. The spaces between the trabeculae are occupied by phagocytic cells containing large membrane-bound vacuoles representing engulfed silicone oil. Some vacuoles appear to be lying free and some contain a slightly flocculent material. The nature of this electron-dense rim is not clear but possibly represents remnants of alternated phagocyte cytoplasm.

Glutaraldelyde/OsO $\mathrm{O}_{4} /$ uranyl acetate/lead citrate $(\times 4900)$ 
the meshwork, however, were largely obliterated by macrophages containing empty vacuoles of varying size (Figs. 6 and 7). Also present were rounded accretions of flocculent material surrounded by a slightly more electron-dense rim. The rim did not have the appearance of a cell membrane, and, although its precise significance is unknown, similar structures have been described following experimental intravitreal oil injection in the monkey (Mukai et al., 1975).

Lens. Anteriorly there was no detectable abnormality apart from phagocytes containing empty vacuoles adherent to the capsule (Fig. 8). Similar cells were also seen posteriorly, where in addition there were foci of subcapsular lenticular fibre degeneration manifested as swelling with increased electron lucency (Fig. 9). Vacuoles comparable to those seen in macrophages and in the filtration angle were not present within the substance of the lens.

Retina. The retinal surface was covered by a generally homogeneous layer of moderate electron density embedded in which were spheroidal droplets of greater electron density. Deep to this acellular

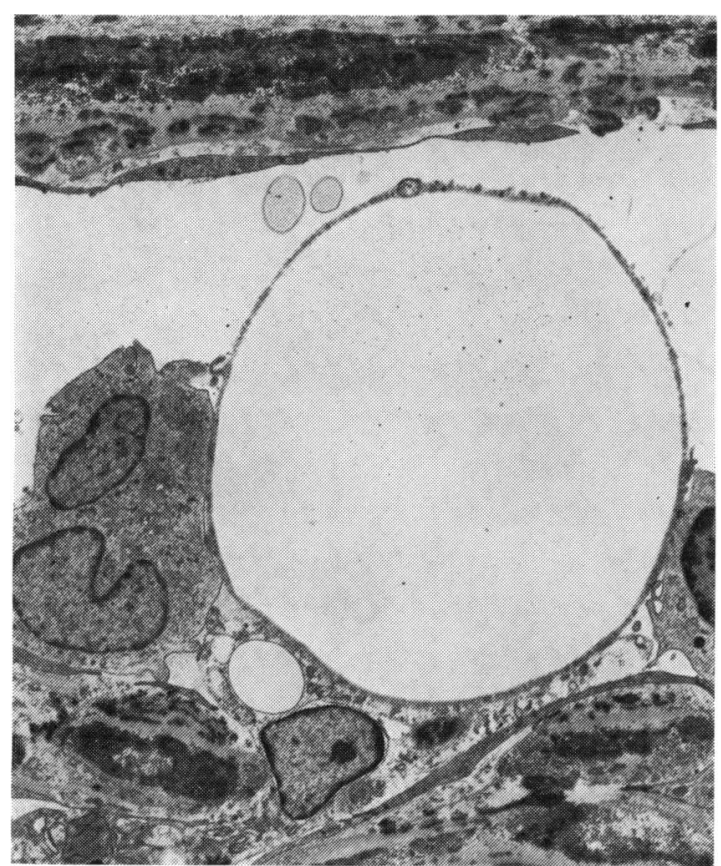

Fig. 7 Trabecular meshwork showing phagocytic cells between the collagenous trabeculae. One such cell contains a massive vacuole covered for the larger part by a narrow rim of cytoplasm only. Other free-lying small globules of flocculent material with a slightly more electron-dense rim are also present. Glutaraldelyde $\left|\mathrm{OsO}_{4}\right|$ uranyl acetate $/$ lead citrate $(\times 3000)$

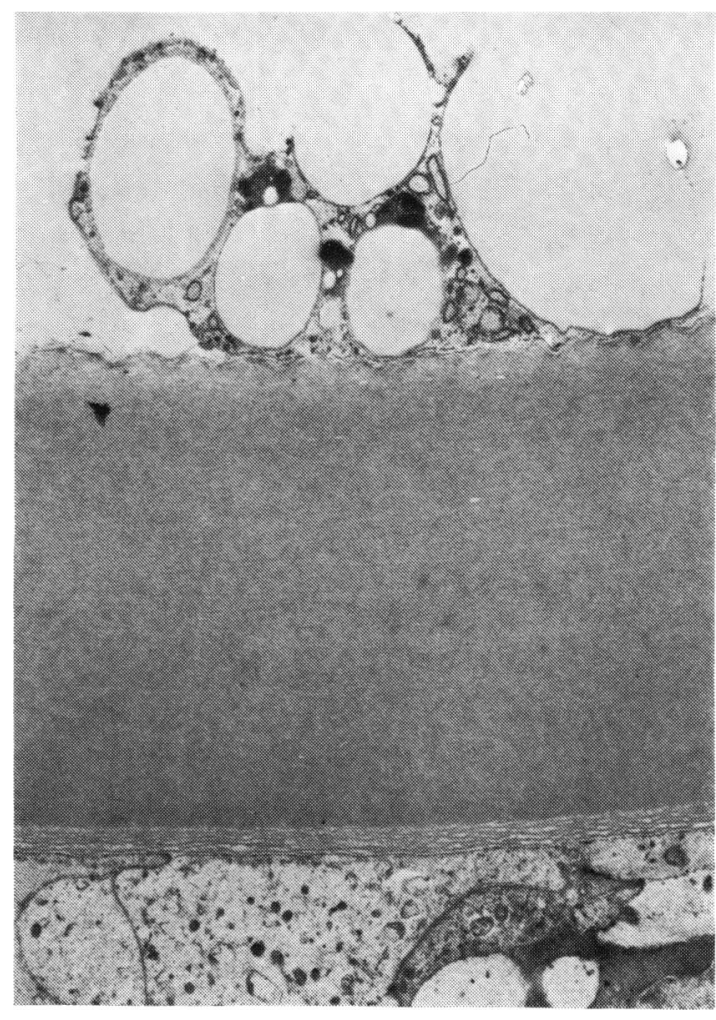

Fig. 8 Part of a phagocytic cell with large vacuolar inclusions presumed to represent engulfed silicone oil attached to the anterior lens capsule. The capsule, basement membrane, and epithelium of the lens, however, show no evidence of infiltration by the oil.

Glutaraldelyde/OsO $\mathrm{O}_{4} /$ uranyl acetate/lead citrate $(\times 4900)$

covering there were aggregates of phagocytic cells containing vacuoles of varying size identical to those previously described in the anterior segment (Fig. 10). A few similar electron-lucent vacuoles were present in the inner layers of the retina, deep to the inner limiting membrane, and appearing to be both intra- and extracellular. Such vacuoles were generally smaller than those on the surface of the retina, while those which were intracellular were within Müller's cells.

\section{Discussion}

Although the results of this study confirm the findings of previous workers that silicone oil injection is associated with a high risk of complications (Watzke, 1967; Okun, 1968; Cockerham et al., 1969; Grey and Leaver, 1977), many of these could be expected to occur after unsuccessful conventional procedures and in association with long-standing 


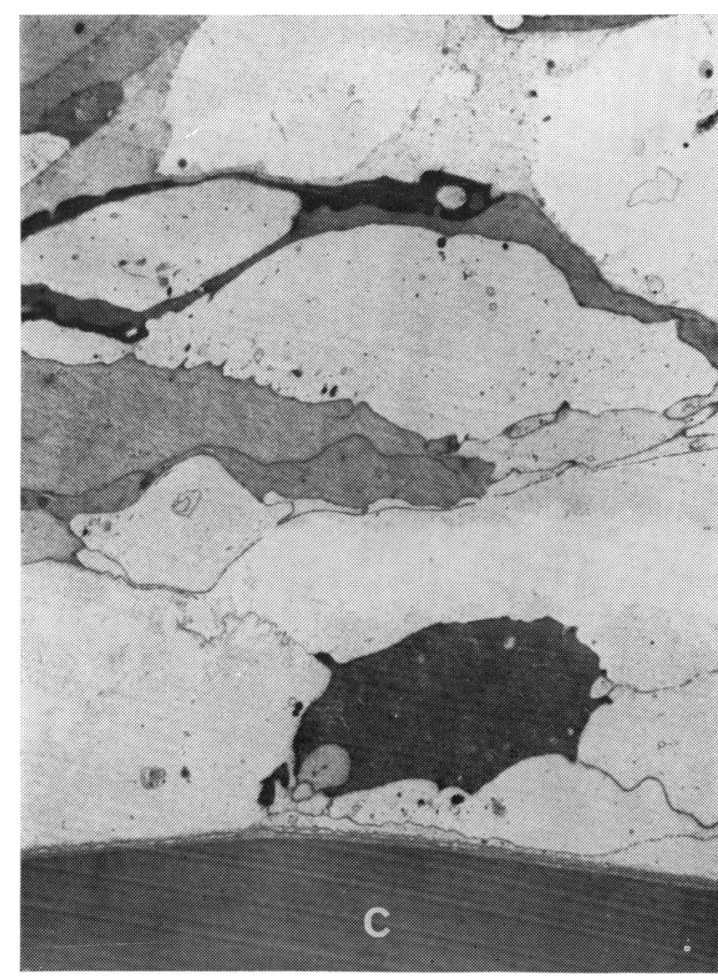

Fig. 9 Some of the posterior fibres of the lens are degenerate and unusually electron-lucent $(C=$ posterior lens capsule). Glutaraldelyde/Os $\mathrm{O}_{4} /$ uranyl acetate/lead citrate $(\times 2400)$

complicated retinal detachments. Close analysis of our findings shows that the improvement in visual function associated with successful reattachment of the retina by this method is maintained in the majority of cases (Fig. 4) and that complications, when they occur, do not necessarily cause progressive visual deterioration.

In common with those of Okun (1968) our findings confirm that cataract is the commonest late complication of silicone oil injection (Table 1), but the lens changes are not usually dense enough to cause loss of navigating vision. No evidence of silicone oil particles within the substance of the lens was demonstrated in our specimen. The lens changes appeared to be due not to any toxic effect of silicone oil on the lens fibres but to deposition of silicone-laden macrophages on the surface of the lens capsule preventing normal metabolic exchange (Figs. 8 and 9).

The presence of silicone oil particles in the angle of the anterior chamber was a common finding, but the incidence of raised intraocular pressure was not high and did not usually appear to be related to the presence of oil in the angle, an observation previously reported by Watzke (1967), while in several cases raised pressure was present in this or the fellow eye before surgery. Fine particles of silicone oil may be released into the anterior chamber by rupture of silicone-oil-laden macrophages which have migrated forwards from the bubble present in the retrohyaloid space. This finding is as common in phakic as it is in aphakic eyes, and it seems probable that the presence of a large number of such particles within the trabecular meshwork could cause obstruction to aqueous outflow. In this series, however, while more than half of the eyes with raised intraocular pressure had oil particles in the anterior chamber angle, in two-thirds of these there was angle closure or evidence of pre-existing glaucoma.

In a few aphakic eyes in which there was a dehiscence in the vitreous remnant a large globule of

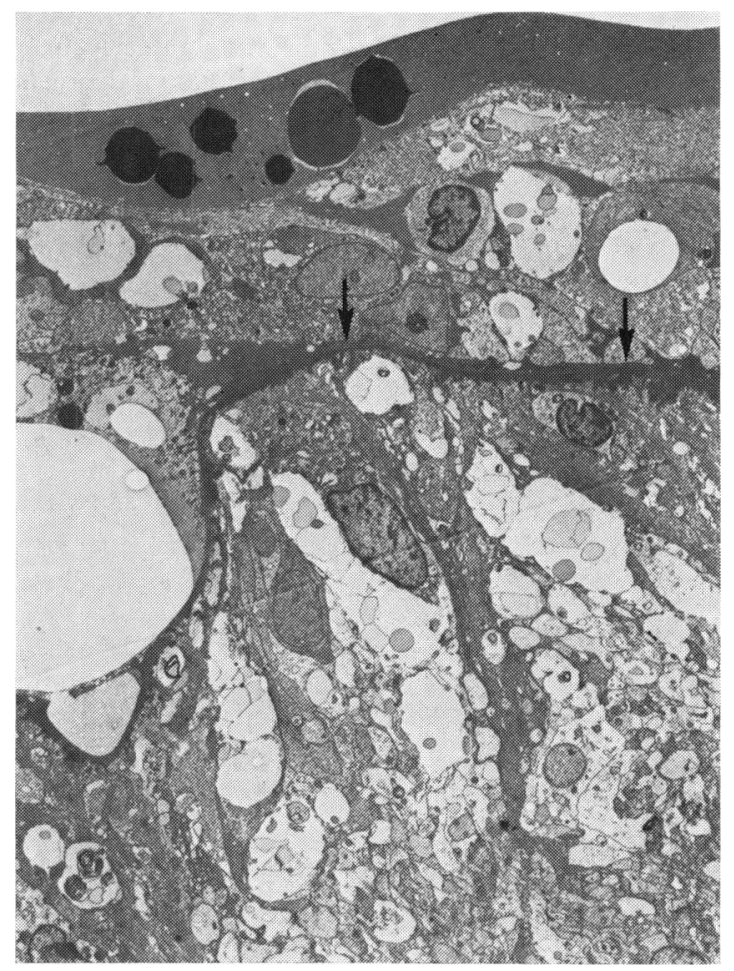

Fig. 10 Electron micrograph of the inner retina, the inner limiting membrane of which (arrows) is overlaid by a homogeneous layer of moderate electron density containing globules of greater density and phagocytic cells containing vacuoles comparable to those seen in the trabecular meshwork and elsewhere. Vacuoles, some apparently empty and others containing amorphous material, are also present within the nerve-fibre layer of the retina. Glutaraldelyde/OsO $\mathrm{O}_{4} /$ uranyl acetate/lead citrate $(\times 1500)$ 
silicone fluid came forward into the anterior chamber after surgery, causing a severe and often painful keratopathy (Fig. 2). This complication can also occur occasionally in phakic eyes undergoing surgical procedures subsequent to the injection of silicone oil (Fig. 3b) or after trauma (Sugar and Okamura, 1976).

In contrast the commoner finding of a fine emulsion of silicone oil particles in contact with the corneal endothelium did not cause any clinically recognisable corneal disease. The histological findings in our case showed that small silicone oil particles were taken up by the endothelial cells but did not migrate into the corneal substance or cause pathological changes in Descemet's membrane or the stroma. We therefore presume that the adverse effect of the large silicone oil bubble was due to its obstructive effect, like that seen on the anterior and posterior lens surfaces.

While no toxic effect of silicone oil was demonstrated, the case for attributing cataract, glaucoma, and keratopathy to a purely obstructive mechanism is strengthened by the fact that these complications can be satisfactorily managed by standard methods. In a recent review of complications after silicone oil injection (Leaver et al., 1978) we reported the results of treatment in 25 eyes in which successful management by extracapsular cataract extraction, medical treatment of glaucoma, and removal of large oil globules from the anterior chamber was accomplished in most cases.

Histological examination of the retina showed fine silicone oil particles within the retinal substance like those shown by Mukai (Mukai et al., 1972). However, in common with those seen elsewhere in this specimen, these particles appeared to be contained within macrophages and glial cells rather than within the neurosensory elements of the retina, the latter appearing to be essentially unaffected.

In only 4 eyes in which the retina remained reattached throughout the follow-up period and in which the initial visual improvement was not maintained was there no evidence of cataract, glaucoma, or keratopathy (Fig. 4). Previous workers have used the electroretinogram response in animal eyes filled with silicone oil both to support (Lee et al., 1969) and to disprove (Armaly, 1962) the hypothesis that late deterioration of vision after successful reattachment of the retina is sometimes caused by silicone retinopathy.

However, the results of electrodiagnostic tests in eyes in which the vitreous has been replaced by an electrical non-conductor cannot be compared to those obtained from intact eyes (Arden, personal communication). In this study we were able to demonstrate a positive ERG response in the majority of eyes in which this test was undertaken, although the potentials were low compared with the normal and the electro-oculogram showed a light rise in one instance only. It would be unwise to draw any conclusions from these results, and, although the possibility of silicone retinopathy exists, we did not find firm evidence from which to make this diagnosis.

We conclude that, while the technique of silicone oil injection is associated with a high risk of longterm complications, particularly cataract, the severity of these and their effect on the maintenance of visual improvement after surgery is frequently minimal, while navigating vision is well preserved. Furthermore, when late complications require treatment, this can be successfully accomplished by standard methods.

We are grateful to $\mathrm{Mr}$ Lorimer Fison and the consultant surgeons at Moorfields Hospital who kindly allowed us to study the patients under their care and to Mr David McLeod for help and encouragement in the preparation of this paper. We thank Mr T. Tarrant and the Department of Audiovisual Communications, Institute of Ophthalmology, Judd Street, London, WC1, and Mr K. Sehmi for their help with the illustrations. Miss Christine Giffen and Miss Heather Lucas kindly provided valuable secretarial assistance.

\section{References}

Armaly, M. F. (1962). Ocular tolerance to silicone. I. Replacement of aqueous and vitreous by silicone fluids. Archives of Ophthalmology, 68, 390-395.

Cockerham, W., Schepens, C. L., and Freeman, H. M. (1969). Silicone injection in retinal detachment. Modern Problems in Ophthalmology, 8, 525-540.

Grey, R. H. B., and Leaver, P. K. (1977). Results of silicone oil injection in massive preretinal retraction. Transactions of the Ophthalmological Societies of the United Kingdom, 97, 238-241.

Grey, R. H. B., and Leaver, P. K. (1979). Silicone oil in treatment of massive preretinal retraction. I. Results in 105 eyes. British Journal of Ophthalmology, 63, 355-360.

Leaver. P. K., Grey, R. H. B., and Garner, A. (1978). Complications following silicone oil injection. Proceedings of the XIth Meeting of the Club Jules Gonin, Barcelona, Spain (in press)

Lee, P. F., Donovan, R. H., Mukai, N., Schepens, C. L., and Freeman, H. M. (1969). Intravitreous injection of silicone, an experimental study. I. Clinical picture and histology of the eye. Annals of Ophthalmology, 1, 15-25.

Mukai, N., Lee, P. F., and Schepens, C. L. (1972). Intravitreous injection of silicone, an experimental study. Annals of Ophthalmology, 4, 273-287.

Mukai, N., Lee, P. F., Oguri, M., and Schepens, C. L. (1975). A long-term evaluation of silicone retinopathy in the monkey. Canadian Journal of Ophthalmology, 10, 391-401.

Okun, E. (1968). Intravitreal surgery utilising liquid silicone: a long-term follow-up. Transactions of the Pacific Coast Oto-Ophthalmological Society, 49, 141-159.

Sugar, H. S., and Okamura, I. D. (1976). Ocular findings 6 years after intravitreal silicone injection. Archives of Ophthalmology, 94, 612-615.

Watzke, R. C. (1967). Silicone retinopiesis for retinal detachment: a long-term clinical evaluation. Archives of Ophthalmology, 77, 185-196. 